\title{
Interactive comment on "Influence of hydrodynamic mixing on the distribution of dissolved organic carbon in the East China Sea and the northwest Pacific" by Ling Ding et al.
}

\section{Anonymous Referee \#3}

Received and published: 8 January 2019

Ding et al., report dissolved organ carbon (DOC) data for the shelf-edge and slope regions in East China Sea (ECS) and the Kuroshio Extension (KE) in the northwestern North Pacific (NP) during two cruises carried out in 2014-2015. The main goal of this paper is to demonstrate that hydrodynamical processes play an important role in the distribution of DOC as well as of nutrients, impacting primary production and ecosystems functioning in this region (P2, L33-35). The main shortcomings of the manuscript are: (1) No data about nutrients, primary production, nor bacterial abundance or production are presented and discussed to support the main goal of the paper; (2) hydrodynamical processes are investigated mainly using temperature. The authors use the linear correlation between DOC and temperature to demonstrate that hydrodynam-

Printer-friendly version

Discussion paper 
ical processes affect DOC distribution. I don't think this is a good approach since it is well known that vertical profiles of DOC and temperature have the same shape and that DOC accumulates in warmer waters (Carlson et al., 1994; Hansell and Carlson, 2001; Avril, 2002; Hansell, 2002; Santinelli et al., 2013), even if the mechanisms are still unclear. The correlation is therefore only due to DOC accumulation in the surface water when a well-developed thermocline occurs, but the increase in DOC concentration in the surface layer is due to a decoupling between production and consumption processes, the low values in the deep cold waters are mainly due to DOC removal. As a consequence the correlation between DOC and temperature does not give any information about hydrodynamical processes. The authors also use the linear inverse correlation between DOC and dissolved inorganic carbon (DIC) to support that hydrodynamical processes affect DOC distribution, but the correlation can be due to the microbial mineralization of $\mathrm{DOC}$ to $\mathrm{CO} 2$, as a consequence it is expected that in old waters DOC is low and DIC is high, whereas in surface waters DOC is high and DIC is low. The data set is of good quality and the data look interesting, but the paper cannot be published in this form. Most of the data are not presented in the results section and the discussion is confused and the main conclusions are not supported by the data. Most of the discussion should be reworked and additional data should be presented to support that hydrodynamical processes play an important role in the distribution of DOC as well as of nutrients, impacting primary production and ecosystems functioning in this region or the goal of the paper should be changed. The English needs an in depth revision. Some suggestions, specific concerns, and questions are provided below.

Specific comments

Material and methods

Printer-friendly version

P7, L151-153, please indicate the batch of the CRM used, the expected and measured values and the statistics (number of samples analyzed, average values \pm standard deviations).

Interactive comment
Discussion paper

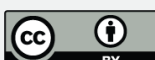


P7, L156-157, if you measured all the samples in duplicate, why don't you report the standard deviation on the vertical profiles in Figure 3?

OSD

Results

All the data discussed in the paper should be briefly described in this section, not only DOC and physical parameters (T and S). AOU, DIC and DIC $\triangle 14 \mathrm{C}$ data are not presented at all.

P9, L206-209. This sentence is hard to follow, I recommend to rework it to improve clarity.

Section 3.2. it is really hard to follow the description of vertical profiles of DOC in Figure 3. The profiles are overlapped, making difficult to look at differences among the stations. Values between 700 and $1400 \mathrm{~m}$ at the stations located in the ECS are higher (45-54 $\mu \mathrm{M})$ than those observed in the KE and in the oceans. Why? I think this is an interesting result that would deserve more attention and discussion.

P10, L219. This sentence is not correct, the highest DOC values are at station K2, whereas the lowest ones at station B2.

$\mathrm{P} 10, \mathrm{~L} 224-226$, This sentence is not clear.

Figure 2. There is a mistake in the letters reported above the graphs. I would add to the figure the name of area the profiles refer to (ECS and KE). I would use KE instead of NP, since it is used in the text and the use of a different abbreviation is confounding.

\section{Discussion}

$\mathrm{P} 10, \mathrm{~L} 232-234$. As reported in the general comments, the positive correlation between DOC and temperature does not imply that physical processes affect DOC distribution more than biological properties. Biological properties are also affected by temperature and without data about biological parameters the authors cannot exclude that DOC concentrations is controlled by biological processes.
Interactive

comment
Printer-friendly version

Discussion paper

\section{3}


P10, L237-239. Since this is a part important for the goal of the paper the results from Ge et al., 2016, should be presented and discussed more in depth.

OSD

P11, L242-243. The correlation between DOC and DIC could be explained by the biological mineralization of DOC to $\mathrm{CO} 2$.

P11, L247-248. DOC values below $500 \mathrm{~m}$ in the ECS are higher than in the ocean. This observation would deserve more discussion.

P11, L256-265. This paragraph is very confused and hard to follow. As an example it is not clear how "density showed the water mass in the studied area is composed of mixed Kuroshio and shelf waters."

P11, L256-261. The description of Figure 5 is really confounding. At L261 the authors speak about upwelling intrusion, but the vertical distribution of density does not show any upwelling of waters.

P12, L278-294. It is not clear why the authors report the correlation between DOC and AOU. This correlation just reflects the vertical distribution of the 2 parameters that is driven by both biological and physical processes. In order to investigate the contribution of DOC mineralization to oxygen consumption, the correlation should be investigated in the core of the different water masses, not putting all the data together.

Section 4.2. It is not clear to me what is the main goal of this section. As above reported, the correlation between DOC and temperature and between DOC and DIC does not say anything about the control of DOC distribution by physical processes such as water masses circulation and mixing as stated by the authors at L323-325.

P14, L329-331. It is expected that surface layer is characterized by high DOC concentration, low DIC and high $\triangle 14 \mathrm{C}$-DIC, this observation does not say anything about water masses mixing and its impact on DOC distribution.

P14, L338-339 This sentence is not correct. Usually DOC accumulation occurs in high stratified waters, so it is not clear to me how "deep vertical deep vertical convection
Interactive comment
Printer-friendly version

Discussion paper 
possibly affected the DOC accumulation [... .]"

P15, L351-364. Looking at figure 8, it is clear from salinity vertical distribution the OSD occurrence of a layer characterized by a salinity minimum at about $700-1000 \mathrm{~m}$. No clear pattern in DOC distribution is observed, indicating that there is no link between the occurrence of this water mass and DOC distribution. In addition, DOC at station B8 shows high values up to $1500 \mathrm{~m}$, but there is no clear correspondence with the occurrence of different water masses, nor with the water column structure.

P15, L364-366 It is not clear to me, how using dissolved inorganic radiocarbon measurements the authors demonstrated the "same strong influence of the southward Oyashio-transported subarctic intermediate water mass via meso-scale eddies [...]".

P16, L381, The authors discuss DOC data in the KE region, but they don't discuss the data in ECS, that in my opinion deserve more attention since the values are higher than those usually observed in deep waters.

P16, L388-390. If radiocarbon data on DOC are available they should be included in the paper and discussed.

Interactive comment on Ocean Sci. Discuss., https://doi.org/10.5194/os-2018-78, 2018.

Printer-friendly version

Interactive

comment

\section{Discussion paper}

